\title{
Does Market Timing Contribute to the Cattle Cycle?
}

\author{
Stephen F. Hamilton And Terry L. Kastens
}

\begin{abstract}
Recent evidence suggests that cyclical cattle inventories are driven by exogenous shocks. This article examines a second possible contributing factor to the cattle cycle: a market timing effect that arises from individual attempts to maintain countercyclical inventories. The model uncovers an important conceptual point: to the extent that cycles are driven by exogenous shocks, a representative producer should outperform one who maintains a constant inventory; whereas, for cycles induced by market timing, a representative producer should underperform one with a constant inventory. Simulated net returns over 1974-98 reveal that a constant-inventory manager significantly outperformed the representative U.S. producer, which indicates that market timing influences the cattle cycle.
\end{abstract}

Key words: biological lags, cattle cycle, exogenous shocks.

One of the most pervasive features of cattle production is the cattle cycle. For at least the last one hundred years, U.S. beef cattle stocks have cycled periodically between periods of high and low inventory numbers. Economists have long suspected that an important feature that drives the cattle cycle is the biological lag in meat production and in herd rebuilding. Calves born in a given year do not impact the meat supply until they are slaughtered as fed cattle, typically one to two years later, and heifer calves retained for replacement in a given year must mature before bearing calves of their own. These biological lags lead to rigidities in the accumulation of breeding stock and limit the ability of producers to respond to changes in market prices.

Jarvis was among the first to examine how cattle investment decisions interact with biological production lags in the cattle cycle. Others have since developed analyses along similar lines (Rucker, Burt, and LaFrance; Foster and Burt; Rosen). These studies have contributed to understanding the biological nature of the cattle cycle, although the process in which actual price and inventory cycles are determined has remained somewhat elu-

Stephen F. Hamilton is an associate professor in the Department of Agricultural and Resource Economics at the University of Arizona. Terry L. Kastens is an assistant professor in the Department of Agricultural Economics at Kansas State University.

This research has benefited from helpful comments by Kevin Dhuyvetter, Tom Marsh, Ted Schroeder, and two anonymous referees for $A J A E$. sive. Recently, Rosen, Murphy, and Sheinkman provide evidence that cyclical responses to exogenous shocks in the cattle industry are consistent with maximization behavior. Given the inherent lags in the inventory rebuilding decision, they show that optimal industry responses to a systematic pattern of demand and supply disturbances lead to a cycling of aggregate inventory levels.

This article provides evidence of a second factor that contributes to the cattle cycle, a factor we refer to as a "market timing" effect. The market timing effect stems from the perceived independence between individual output and market prices in a competitive industry: a competitive producer views aggregate output to be independent of his or her own output choice. Consequently, the biological lag in the accumulation of aggregate inventory provides an individual producer with the incentive to forego sales in periods of large industry output and low prices in order to increase sales in subsequent industry rebuilding periods of low output and high prices. That is, cycles in aggregate inventory levels provide an individual producer with an incentive to "time the market," or to deviate from the aggregate movement of the cycle by behaving "countercyclically."

Previous studies have suggested that countercyclical inventory management may be optimal. A notable example is Trapp, who shows that the optimal management strategy for a cow-calf producer with perfect foresight 
over future price realizations is to build a large inventory in advance of the cyclical peak in price. Trapp considers the management decision of an individual agent whose production decision has no effect on market prices. This article explicitly considers the relationship between individual and aggregate output and endogenizes the price determination process through a specification of market demand. ${ }^{1}$ This specification allows us to isolate two independent effects that potentially influence the cattle cycle: an exogenous shock effect that shifts the demand function, itself, and a market timing effect that represents the aggregate quantity (and price) movement along a particular, dynamically stable demand function. ${ }^{2}$

The identification of a potential market timing effect reveals a major conceptual point regarding economic performance in the face of cyclical prices. Specifically, if cycles derive entirely from exogenous shocks, as in Rosen, and Rosen, Murphy, and Sheinkman, then a cyclical industry response to these shocks maximizes aggregate expected profit. It follows that a representative producer in the economy, whose inventory follows that of the U.S. cattle cycle, should outperform, on average, a producer who deviates from the aggregate to maintain a constant inventory. However, if demand and cost conditions are dynamically stable, as in the case where cycles occur purely through market timing effects, we show that the representative producer always underperforms a producer who maintains a constant inventory over time. This conceptual observation suggests a direction for empirical examination that relies on an analysis of net returns from alternative inventory management regimes in the U.S. cattle cycle.

In the empirical section of the article, a simulation model of net returns is constructed over roughly 2.5 cycles in the $1974-98$ period. The period of study spans several seasons in which large, national shocks in feed prices occurred and at least potentially includes demand shocks due to health concerns regard-

\footnotetext{
${ }^{1}$ That is, the article "closes the economic system" by making it impossible for all producers in the economy to be countercyclical simultaneously.

${ }^{2}$ Throughout, we refer to the market timing effect rather generically as any effect that induces cyclical price responses through movements along a stable demand function. Thus, the term "market timing" may refer to an output sequence that stems from a planned choice (i.e., a countercyclical management strategy) or from a constrained choice (e.g., a credit constraint) that forces sales to be made at various times.
}

ing beef consumption in the early 1980s. Thus, the data capture exogenous shock effects. Nonetheless, despite these random market disturbances, an analysis of profitability reveals that a manager who held a constant inventory significantly outperformed a representative U.S. producer over the period. This finding provides evidence that a market timing effect may, in fact, exert an important influence on the formation of the cattle cycle.

\section{Market Timing and Exogenous Shocks}

To clarify the distinction between an exogenous shock effect and a market timing effect, consider for a moment the demand side of a market. Suppose the market price unexpectedly decreases in a certain period. Given a demand function, there are, in general, two types of effects that may explain this price decrease: a change in demand and a change in quantity demanded. For a producer, the factor inducing the change in price is contemporaneously identified only with knowledge of both the supply function and the aggregate production level of the economy. Rosen, Murphy, and Sheinkman consider the cattle economy at just such a highly aggregated level, and, as a result, eliminate all but the exogenous shock effect in their model. ${ }^{3}$ However, when production decisions are disaggregated, an individual producer is incapable of discriminating between a contemporaneous price decrease caused by a change in demand and that induced by a change in quantity demanded. ${ }^{4}$ Thus, whenever biological lags exist, an individual producer who views a price decrease to be caused by increased aggregate output may have an incentive to reduce current output and rebuild stocks for subsequent periods of high prices.

Next, consider the case of a change in quantity demanded from the supply side of the market. Suppose, as above, that the market price decreases in a certain period. On the supply side, the contemporaneous supply function can shift outward in response to either an exogenous shock that lowers the marginal cost of production or, when biological lags exist, to an industry liquidation of aggregate inventory. Indeed, as Jarvis observes, the

\footnotetext{
${ }^{3}$ For a producer who controls aggregate output, an unanticipated price change can never occur from a movement along a demand curve.

${ }^{4}$ The idea is related to the signal extraction problem originally considered by Lucas.
} 
supply function in the cattle industry depends not only on the marginal cost of production but also on the consumption of fixed cattle stocks. A producer who views the shift in supply (and the commensurate price decrease) to be caused by aggregate inventory liquidation has an incentive to reduce current output and thereby increase output in subsequent periods of inventory rebuilding. This is the market timing effect.

There is evidence that the market timing effect derives from two sources: planned choices and constrained choices. Trapp demonstrates that an individual cow-calf producer has an incentive to engage in planned market timing by maintaining a countercyclical cattle inventory. Alternatively, Bierlen, Barry, Dixon, and Ahrendsen provide evidence that credit constraints force certain producers to adjust their cattle inventories to meet cash flow requirements at various, and perhaps inopportune, times.

The planned actions of individual producers to "time the market" do not necessarily dampen cyclicality induced by exogenous shocks. In environments without market disturbances, Hayes and Schmitz demonstrate that attempts to behave countercyclically lead to familiar cobweb price responses that dampen the amplitude of a cycle. In markets subject to random events, however, countercyclical management can either dampen or exacerbate the cattle cycle, depending on the nature of the exogenous shocks. As Rosen demonstrates, the optimal industry response to a transitory shock that increases price is to increase contemporaneous sales, while the optimal industry response to a permanent shock is to decrease current sales in order to rebuild the breeding stock inventory for subsequent periods of high prices. A planned market timing effect always leads producers to increase sales in periods of high prices. Accordingly, producer attempts to "time the market" dampen inventory cycles arising from permanent demand shocks by "smoothing out" the aggregate inventory adjustment, whereas, for cycles induced by transitory shocks, a planned market timing effect exacerbates the cycle by magnifying the industry increase in output.

\section{The Conceptual Model}

The theoretical development begins by constructing an equation of motion to define the evolution of cattle inventory over time. The foundation of the model rests on several stylized features of the breeding stock: there is a one-year gestation-birth delay among adult cows and a one-year maturation lag for replacement heifers retained in the inventory as calves. For tractability, several simplifications are imposed. In particular, the model employs constant fecundity and death rates over time and considers a homogeneous cow population in which such rates are independent of age or prior fertility.

Let $x_{t}$ denote the breeding stock of an individual cow-calf producer in period $t .^{5}$ The head count of the entire cattle stock in period $t, y_{t}$, is the sum of the breeding stock plus the heifer calves retained for replacement,

$$
y_{t}=x_{t}+\rho_{t},
$$

where $\rho_{t}$, the heifer calves retained in period $t$, enter the breeding stock upon maturation at $t+1$. Next, let $g$ denote the rate of live births in the breeding stock and $\beta$ represent the proportion of live births that are female calves. Given the one-period gestation lag, it follows that a total of $g x_{t-1}$ calves are born at $t$, of which $(1-\beta) g x_{t-1}$ are steers and $\beta g x_{t-1}$ are heifers. Of the calves born at $t$, all steer calves are sold, which implies

$$
s_{t}=(1-\beta) g x_{t-1},
$$

where $s_{t}$ denotes the number of steer calves sold in the spot market. Heifer calves are either sold or retained as replacements, such that

$$
h_{t}+\rho_{t}=\beta g x_{t-1},
$$

where $h_{t}$ denotes the number of heifer calves sold in the period $t$ spot market.

At $t+1$, each surviving cow from period $t$ must either be culled or retained in the breeding stock. Heifers retained as replacements at $t$ reach maturation at $t+1$, hence

$$
c_{t+1}+x_{t+1}=(1-\gamma) x_{t}+\rho_{t},
$$

where $\gamma$ denotes the rate of death of the breeding stock and $c_{t+1}$ is the number of adult cows culled. Substitution of equation (3) into equation (4) yields the following equation of motion:

$$
x_{t+1}=(1-\gamma) x_{t}+\beta g x_{t-1}-h_{t}-c_{t+1} .
$$

\footnotetext{
5 Throughout, lower-case characters are generally used to describe variables under the control of an individual agent while upper-case characters describe aggregate industry levels.
} 
Equation (5) describes the population dynamics that govern a producer's breeding stock inventory according to survivorship of the existing stock, the addition of heifer replacements, and the culling of adult cows from the herd.

A cow-calf producer chooses between selling and retaining both heifer calves and adult cows. The decision to sell an additional cow or calf generates additional revenue in the current period, but reduces the breeding stock through equation (5), which leads to lower steer calf sales and a smaller pool of female calves to divide between replacement and sale in subsequent periods. Thus, the economic decision to retain or sell an extra cow or calf is based on the relationship between current and expected future prices as well as on the projected stream of production costs.

The costs of cattle production are divided into two components: unit feed costs paid on each animal in the cattle inventory, and costs associated with breeding stock maintenance. Let $m_{t}$ denote the unit feed cost in period $t$ and define $k_{t}\left(x_{t}\right)$ to be the total cost of maintaining the breeding stock, which includes the cost of breeding bulls, labor, and other specialized inputs not included in feed cost. Next, define the producer's profits at $t, \pi_{t}$, to be revenues minus feed costs and maintenance costs, such that

$$
\pi_{t}=P_{t}^{H} h_{t}+P_{t}^{S} s_{t}+P_{t}^{C} c_{t}-m_{t} y_{t}-k_{t}\left(x_{t}\right),
$$

where $P_{t}^{H}, P_{t}^{S}$, and $P_{t}^{C}$ denote the market price of heifer calves, steer calves, and cull cows in period $t$, respectively. Making appropriate substitutions from equations (1), (2), and (3) obtains

$$
\begin{aligned}
\pi_{t}= & P_{t}^{H} h_{t}+P_{t}^{S}(1-\beta) g x_{t-1}+P_{t}^{C} c_{t}-m_{t} \\
& \left(x_{t}+\beta g x_{t-1}-h_{t}\right)-k_{t}\left(x_{t}\right) .
\end{aligned}
$$

Defining $\mathrm{E}_{t}$ to be the expectation operator given all information available at $t$, and letting $V_{t}$ represent the market value of the jointly determined production sequences $\left\{h_{t}\right\},\left\{c_{t}\right\}$, and $\left\{x_{t}\right\}$, the value-maximizing outcome is completely characterized as the solution to

$$
\begin{gathered}
\max _{\left\{h_{t} \geq 0, c_{t} \geq 0, x_{t}>0\right\}} V_{t}=\mathrm{E}_{t} \sum_{\tau=0}^{\infty} \pi_{t+\tau}(1+r)^{-\tau} \\
\text { s.t. } x_{t+\tau}=(1-\gamma) x_{t+\tau-1}+\beta g x_{t+\tau-2}-h_{t+\tau-1}-c_{t+\tau} .
\end{gathered}
$$

Next, let $\lambda_{t}$ denote the multiplier associated with the constraint in equation (7), so that the optimal production sequences satisfy the following first-order conditions:

$$
\begin{aligned}
& \mathrm{E}_{t}\left\{P_{t+\tau}^{H}+m_{t+\tau}-(1+r)^{-1} \lambda_{t+\tau+1}\right\} \leq 0, \\
& \mathrm{E}_{t}\left\{P_{t+\tau}^{C}-\lambda_{t+\tau}\right\} \leq 0, \\
& \mathrm{E}_{t}\left\{(1+r)^{-2} \beta g \lambda_{t+\tau+2}+(1+r)^{-1}\right. \\
& \quad\left[(1-\beta) g P_{t+\tau+1}^{S}-\beta g m_{t+\tau+1}+(1-\gamma) \lambda_{t+\tau+1}\right] \\
& \left.\quad-\left[m_{t+\tau}+k^{\prime}\left(x_{t+\tau}\right)+\lambda_{t+\tau}\right]\right\}=0, \text { for all } \tau .
\end{aligned}
$$

Equation (10) expresses the optimal breeding stock level in terms of expected steer calf prices and shadow values of the breeding stock, while equations (8) and (9) are KuhnTucker conditions that are met with equality whenever $h_{t}>0$ and $c_{t}>0$. Combining equations (8) and (9) and noting that $\mathrm{E}_{t}\left\{P_{t}^{H}\right\}=$ $P_{t}^{H}$ and $\mathrm{E}_{t}\left\{m_{t}\right\}=m_{t}$, we find that if

$$
P_{t}^{H}+m_{t}<\mathrm{E}_{t}\left\{(1+r)^{-1} P_{t+1}^{C}\right\}
$$

then optimal inventory management involves the sale of only cull cows (and no heifer calves) at $t$, whereas, if price expectations satisfy

$$
P_{t}^{H}+m_{t}=\mathrm{E}_{t}\left\{(1+r)^{-1} P_{t+1}^{C}\right\}
$$

then the cow-calf operator is indifferent on the margin between selling heifer calves and culling adult cows. The intuition for this result is straightforward. For example, if $P_{t}^{H}+m_{t}<$ $\mathrm{E}_{t}\left\{(1+r)^{-1} P_{t+1}^{C}\right\}$, as in equation (11), then the producer should make no sales of heifer calves in period $t$, but, instead, retain each calf as an investment that grows into an adult cow in period $t+1$, because doing so provides a rate of return net of feed inputs, $m_{t}$, that exceeds the rate of discount. In equation (12), the expected present value of a cull in period $t+1$ exactly equals the sum of the heifer calf price plus feed cost in period $t$, which implies that the producer is indifferent between the sale of a heifer calf at $t$ and the sale of an adult cow at $t+1$. Throughout, attention is generally confined to the case in which a positive fraction of both heifer calves and adult cows are sold in all periods, which corresponds with the situation in equation (12). This razor edge outcome occurs in the model due to homogeneity of cattle stocks (i.e., the abstraction from age cohorts), yet has fairly innocuous implications on the cattle inventory decision. To see this, note that the dynamic flow of inventory in equation (5) is independent of whether a female member of the herd is 
sold as a heifer calf at $t$ or as an adult cow at $t+1 .^{6}$

Combining equations (10) and (12), we arrive at the period $t$ inventory decision:

$$
\begin{aligned}
& \mathrm{E}_{t}\left\{(1+r)^{-2}\right. {\left[\beta g P_{t+2}^{H}+(1-\beta) g P_{t+2}^{S}\right.} \\
&\left.\left.+(1-\gamma) P_{t+2}^{C}\right]\right\}=\mathrm{E}_{t}\left\{(1+r)^{-1}\right. \\
& \\
& {\left.\left[m_{t+1}+k_{t+1}{ }^{\prime}\left(x_{t+1}\right)\right]\right\}+P_{t}^{H}+m_{t} . }
\end{aligned}
$$

Equation (13) defines the inventory decision in terms of the marginal decision to hold or sell an additional heifer calf. The optimal breeding stock inventory in equation (13) occurs at the point where the expected marginal benefit of a retained calf, the discounted value of additional progeny plus the salvage value of a cull at $t+2$, equals the expected marginal cost of holding an additional cow in the stock, which sums current opportunity cost and unit feed cost at $t$ plus the expected discounted feeding and maintenance costs at $t+1$. Given a producer's expectations of future prices, equation (13) uniquely defines the optimal breeding stock to maintain at $t$ in a competitive market, which is denoted $x_{t}^{*}$.

The optimal sequence of breeding stock to maintain depends on expectations of future prices, which are functions of aggregate industry variables in the economy. For concreteness, let $X_{t}=\sum_{i} x_{i t}, H_{t}=\sum_{i} h_{i t}$, and $C_{t}$ $=\sum_{i} c_{i t}$ denote the aggregate level of breeding stock, heifer calf sales, and cull cow sales in the economy for all producers $i$ in period $t$. It is then possible to define the inverse demand functions as $P_{t}^{H}=P^{H}\left(H_{t}, \theta_{t}^{H}\right)$, and $P_{t}^{C}$ $=P^{C}\left(C_{t}, \theta_{t}^{C}\right), P_{t}^{S}=P^{S}\left[(1-\beta) g X_{t-1}, \theta_{t}^{S}\right)$, respectively, where $\theta_{t}^{j}, j \in H, C, S$, are a shift parameters that reflect exogenous shocks, and where $\partial P^{j} / \partial_{j}<0$ and $\partial P^{j} / \partial \theta^{j}>0$ are satisfied for all $j$. With a similar construction, Rosen has demonstrated that a transitory demand shock reduces the optimal breeding stock at the industry level and increases consumption in the period in which a positive shock occurs. Aggregating equation (13) across $n$ representative producers, the same result occurs here for an innovation in $\theta_{t}^{j}{ }^{7}$

The central result of Rosen, Murphy, and Sheinkman is that distributed lags created by

\footnotetext{
${ }^{6}$ For the case in which the expected discounted cull price in period $t+1$ always exceeds the period $t$ heifer calf price plus unit feed costs, the inventory dynamics in equation (5) roughly correspond to the consumption sequence of adult stocks treated by Rosen, and Rosen, Murphy, and Scheinkman.

${ }^{7}$ The outcome would also involve a degree of switching in the allocation of sales between the heifer calf and adult cull markets unless the demand shock was proportionally distributed across commodities.
}

the moving average component of an aggregate breeding stock equation explain the cyclical nature of total stocks in a linear economy. Specifically, aggregating equation (13) to the industry level and incorporating linear versions of the above demand functions, it is possible to generate inventory cycles at the industry level as optimal responses for known functional specifications of demand and cost shocks. Thus, exogenous shock effects at the aggregate level induce an optimal response of cyclicality.

Given that cycles exist in the cattle industry due to exogenous shock effects, there is a possibility that a second effect, a market timing effect, also contributes to the formation of cycles. The market timing effect stems either from the planned choice of an individual output sequence (i.e., a countercyclical management strategy) or from a constrained choice (e.g., a credit constraint) that forces sales to be made at various, perhaps inopportune, times. In the context of our model, it is possible to show that an incentive for a planned market timing effect exists. Specifically, from the perspective of an individual competitive producer, who, as an atomistic firm, views his or her own output decision as unrelated to the market price, it is possible to show that the optimal response to an aggregate inventory cycle under stable market conditions is countercyclical inventory management. Defining a stock that varies inversely with the expected value of its corresponding aggregate variable as countercyclical, we have ${ }^{8}$

Proposition 1. With stable, linear demand functions and convex breeding costs, if the expected sequence of aggregate breeding stocks in the economy follows a cycle, then the optimal sequence of breeding stock for an individual producer is countercyclical.

Proposition 1 illustrates a potential source of the market timing effect in the cattle cycle: each producer wishes to manage inventories in an inverse relationship with the aggregate level of the breeding stock. That is, a producer who forms future expectations on aggregate cattle inventory levels in the cattle cycle has an incentive to manage his or her inventory countercyclically.

Proposition 1 has important implications for economic performance in the cattle sector.

\footnotetext{
${ }^{8}$ The proofs of this and the following proposition are available from the authors upon request.
} 
Each individual producer in the economy wishes to rebuild and liquidate his or her breeding stock by maintaining an inventory that is inversely related to the aggregate, yet the aggregate, itself, is defined as the sum of individual breeding stocks. Thus, to the extent that individual producers have access to the same information, and consequently form identical price expectations, countercyclical management is not possible. Moreover, even if producers have heterogeneous information, so that individual expectations of future variables (and responses to changes in contemporaneous variables) differ, the average or representative producer in the economy, by definition, is procyclical. This observation turns out to have important implications for empirical investigation. We return to this result after further examination of the market timing effect.

\section{Economic Performance under a Pure Market Timing Effect}

In this section, attention is confined to circumstances in which demand and cost conditions are stable over time to isolate the market timing effect. To develop the basic insight regarding economic performance when cyclical prices derive from the market timing effect, it is helpful to strip away unnecessary details from the previous model of the cattle industry. Specifically, the analysis is simplified here by considering sales of a single cattle product with constant unit marketing costs. In this case, stable marketing costs over time allow the performance of a producer to be captured by the differences in total revenue. That is, if $m$ denotes unit cost and $q=P-m$ is net profit per unit, then differences in unit profitability among different producers over time depend solely on the average price per head that each producer receives from a given sequence of production.

Consider a cyclical sequence of aggregate heifer calf sales in the economy, $\left\{H_{t}\right\}$, and define the market price at $t$ by the stable inverse demand function $P_{t}=P\left(H_{t}\right), \forall t$. The market price schedule, though it need not be a continuous function, is assumed to obey the law of demand; that is, if $\bar{H}$ denotes the mean level of $H$, then for some $\Delta H_{t}=H_{t}-\bar{H}$ and $\Delta P_{t}=P\left(H_{t}\right)-P(\bar{H})$, inverse demand satisfies $\Delta P_{t} \Delta H_{t} \leq 0, \forall t$.

Suppose that the crop of heifer calves at $t$ is produced by $n$ economic agents, such that $H_{t}$ $=\sum_{i=1}^{n} h_{i t}$, where $h_{i t}$ denotes the output of producer $i$ in period $t$. For an economy characterized by a representative producer, industry output at a particular point in time is described by the condition $H_{t}=n h_{t}$, where the number of producers is assumed to remain constant for simplicity. If the output of each producer is atomistic, as in a competitive market, producers who make the same number of sales in a given time horizon satisfy the following

Proposition 2. If the movement of the aggregate variable $H_{t}$ varies over time, then

(i) a producer who maintains a constant level of output at all points in time, $h_{i t}=\bar{h}_{i}, \forall t$, receives an average price per unit, $\hat{P}_{C}$, that satisfies $\hat{P}_{C}=\bar{P}$.

(ii) a representative producer in the economy receives an average price per unit, $\hat{P}_{R}$, that satisfies $\hat{P}_{R} \leq \bar{P}$, where equality holds only in the case of infinitely elastic demand.

Proposition 2 is quite intuitive. With stable demand conditions over time, prices in the economy are higher than average when the output level of the representative producer is below average, so that the representative producer tends to sell more output in periods of below-average prices and less output in periods of above-average prices. Consequently, the average price per unit received by the representative producer over time is below the statistical average price observed over the production interval. It follows that a producer who does not vary output levels over time receives a higher average price per unit over time than the representative producer in the economy.

The implication of proposition 2 is important. If the total number of sales over time is held constant between alternative management strategies, the representative producer, who makes larger sales in periods of low prices, receives less revenue over time than a manager who maintains a constant inventory. Hence, a representative producer is likely to make lower profit per head than a constant inventory manager when cyclical prices are driven purely by the market timing effect.

Thus, whether the cattle cycle derives from exogenous shock effects (i.e., changes in demand) or from market timing effects (i.e., changes in the quantity demanded) yields precisely opposite implications for economic performance. This conceptual observation 
leads to an interesting empirical possibility, which we summarize with the following hypotheses.

HypOTHESIS 1. If the cattle cycle is driven entirely by exogenous shocks, a representative producer achieves higher net returns over time than a constant inventory manager.

HYPOTHESIS 2. If the cattle cycle is driven entirely by market timing, a representative producer achieves lower net returns over time than a constant inventory manager.

\section{An Inventory-Based Simulation Model of Economic Returns}

To test these hypotheses, we construct a simulation model to calculate net returns from alternative cattle management practices. Historical cost and price data, as well as herd performance criteria (e.g., bull to cow ratio and cattle death rates) were acquired from the Livestock Marketing Information Center (LMIC) annual cowherd business budgets. The model includes an explicit decomposition of production costs. Fixed costs, which vary over time with changes in input prices but not across changes in cattle inventory, include depreciation on buildings and equipment, labor, property taxes, insurance, utilities, repairs on equipment, and relevant interest cost. Variable costs per head include pasture costs, winter feed costs, protein and salt cost, bull cost, veterinary expense, marketing cost $(3 \%$ of total sales revenue), miscellaneous, and relevant interest cost.

Net returns are computed through 2.5 cattle cycles in the 1974-98 period for three hypothetical producers. The first producer is a constant-inventory manager who ignores the cattle cycle entirely and maintains a herd size of exactly $\bar{\chi}$ cows. The second producer is a representative producer who maintains a herd size with an average of $\bar{\chi}$ cows over the 1974-98 period, but expands and contracts the herd annually in proportion to fluctuations in the January 1 U.S. beef cow inventory numbers. ${ }^{9}$ The last producer is a countercy-

\footnotetext{
${ }^{9}$ To isolate cyclical effects, the U.S. inventory series is detrended to account for the decline in cattle numbers over the period. The number of cows in year $t, \chi_{t}$, is taken from the USDA report of the January 1 U.S. beef cow inventory (1974-98), which represents cows that have calved at least once prior to year $t$. Note that this definition differs somewhat from the breeding stock defined earlier, $x_{t}$, which includes both cows that calve for the first time at $t$ and replacement heifers that are to calve for the first time at $t$.
}

clical manager who also maintains an average herd of $\bar{x}$ cows, but expands and contracts herd size in inverse proportion to changes in U.S. inventory. ${ }^{10}$

For the representative producer model, the flow of inventory is adjusted to match the observed fluctuations in U.S. beef cow numbers and annual slaughter levels by selling and retaining additional heifer calves in the stock through the equation of motion (5). ${ }^{11}$ That is, in period $t+\tau$, the ending beef cow inventory is made compatible with the observed beginning U.S. beef cow inventory at $t+\tau+1$ by retaining heifers as necessary in earlier periods to accommodate the change in inventory not explained by observed culls. For the constant-herd-size model, using the same notation established earlier, the restrictions, $\chi_{t+1}=\chi_{t}=\bar{\chi}$ and $c_{t+1}=c_{t}=\bar{c}$, are imposed, from which it follows readily that $h_{t+1}=h_{t}=\bar{h}$ and $s_{t+1}=s_{t}=\bar{s}$ for all $t$. Finally, to derive the flow of inventory for the countercyclical manager, we subtract the deviation in herd size of the representative producer from the baseline inventory of the constant-herd-size manager. Thus, if the representative producer holds a cattle inventory of $\chi_{t}=\bar{\chi}+\varepsilon_{t}$ and culls $c_{t}=\bar{c}+\mu_{t}$ in period $t$, the countercyclical manager holds a period $t$ inventory of $\chi_{t}=\bar{\chi}-\varepsilon_{t}$ and culls $c_{t}=\bar{c}-\mu_{t}$, where $\varepsilon_{t}$ and $\mu_{t}$ are deviations in cattle inventory and culls, respectively.

For compatibility with the LMIC budgets, constant death rates are imposed on adult cows $\left(\gamma^{A}=0.015\right)$, replacement heifers $\left(\gamma^{R}=0.03\right)$, and newborn calves $\left(\gamma^{C}=0.08\right)$, where the latter figure includes all losses from conception to weaning. ${ }^{12}$ For compactness, the notation adopted for the empirical model is presented in table 1 .

The equations that follow describe the core

${ }^{10}$ The performance of the countercyclical manager is unimportant for empirical identification of exogenous shock and market timing effects, and is presented only as a point of comparison for the interested reader.

${ }^{11}$ Prior to 1986 , beef cow slaughter was not separated from dairy cow slaughter in the data. The procedures used by Schmitz were followed to estimate beef cow slaughter for the 1974-85 period. That is, beef cow and dairy cow slaughter numbers were computed from the 1970-98 average beef heifer to beef cow ratio and dairy heifer to dairy cow ratio, respectively. The relative portion of beef cows in each year is then multiplied by annual commercial cow slaughter to yield an estimate of annual beef cow slaughter.

12 Assuming a constant herd size of 100 cows, each exposed to a bull, LMIC reports 8 calves fail to wean (either through conception failure of adult cows or through death of calves), 16 heifer calves are retained as replacements, and 14 culls are sold. The two-animal gap between retained heifers and culls was arbitrarily prorated as representing the death of 1.5 adult cows and 0.5 replacement heifers, which implies $\gamma^{\mathrm{R}}=0.5 / 16$ 
Table 1. Notation and Definitions for the Empirical Model

$\chi_{t} \quad$ Beef cow inventory in period $t$ : cows that have calved at least once

$f_{t} \quad$ Heifers that will calve for the first time in period $t$

$\rho_{t} \quad$ The number of heifer calves retained as replacements in period $t$

$x_{t} \quad$ Total breeding stock in period $t$ : $x_{t}=\chi_{t}+f_{t}+\rho_{t-l}$

$y_{t} \quad$ Total cattle inventory in period $t$ : $y_{t}=x_{t}+\rho_{t}$

$c_{t} \quad$ The number of adult cows culled (sold) in period $t$

$h_{t} \quad$ The number of heifer calves sold in period $t$

$s_{t} \quad$ The number of steer calves sold in period $t$

$\beta$ The portion of total births that are heifer calves

$\gamma^{A} \quad$ Constant annual death loss on adult cows and first-calf heifers: $\gamma^{A}=0.015$

$\gamma^{R} \quad$ Constant annual death loss on replacement heifers: $\gamma^{R}=0.03$

$\gamma^{C} \quad$ Constant annual percent of bred cattle that do not wean a live calf: $\gamma^{C}=0.08$

$\phi \quad$ Number of cows a bull impregnates in a given year: $\phi=29$

$b_{t} \quad$ Number of breeding bulls in period $t$ : $b_{t}=x_{t} / \phi$

$P_{t}^{C} \quad$ Price received on cull cow sales

$P_{t}^{H} \quad$ Price received on heifer calf sales

$P_{t}^{S} \quad$ Price received on steer calf sales

$P_{t}^{B} \quad$ Price paid/received on bulls purchased/sold as needed in period $t$

$\pi_{t} \quad$ Net return in period $t$

$r_{t} \quad$ The market rate of interest at $t$

$V_{t, j}$ The value of a cow of age $i$ in period $t$

$I_{t} \quad$ Investment value of the entire cattle inventory in period $t$

$\psi_{t} \quad$ Total cost of pasture grass in period $t$

$m_{t} \quad$ Total cost of winter feed in period $t$

$\omega \quad$ Marketing cost on sales: $\omega=0.03$

$l_{t} \quad$ Total cost of labor in period $t$

$u_{t} \quad$ Total cost of utilities in period $t$

$a_{t}$ Total cost of equipment repairs in period $t$

$d_{t}$ Depreciation on buildings and equipment, taxes, and insurance in period $t$

of the simulation model. Based on U.S. beef cow inventory numbers, the number of heifers owned by the representative producer that calve for the first time in period $t, f_{t}$ are the heifers needed to replace cows lost through death and culling in period $t$, plus the change in inventory over the period,

$$
f_{t}=c_{t}+\left(\chi_{t}+f_{t}\right) \gamma^{A}+\chi_{t+1}-\chi_{t} .
$$

Manipulating this equation identifies the number of first-calf heifers in period $t$ :

$$
f_{t}=\left(c_{t}+\chi_{t+1}\right) /\left(1-\gamma^{A}\right)-\chi_{t} .
$$

The production sequences $\left\{\chi_{t}\right\}$ and $\left\{c_{t}\right\}$, which are taken exogenously from U.S. January 1 beef cow inventory and annual slaughter data, uniquely define the sequence of first-calf heifers of the inventory of the representative producer.

Use of equation (14) allows the number of steer calf sales to be calculated for the representative producer in period $t$ as

$$
s_{t}=(1-\beta)\left(1-\gamma^{C}\right)\left(\chi_{t}+f_{t}\right)
$$

where the proportion of heifer calf births in the population, $\beta$, is taken as $\beta=0.5$ to reflect an equal likelihood that a cow gives birth to a steer or heifer calf. ${ }^{13}$ Heifer calves born in period $t$ are either sold $\left(h_{t}\right)$ or retained as replacements $\left(\rho_{t}\right)$, which yields

$$
h_{t}+\rho_{t}=\beta\left(1-\gamma^{C}\right)\left(\chi_{t}+f_{t}\right) .
$$

Through the calculation of surviving first-calf heifers (equation (14)) in period $t+2$, the replacement heifers retained in period $t, \rho_{t}$, is identified as

$$
\rho_{t}=f_{t+2} /\left(1-\gamma^{R}\right)
$$

Substitution of equation (16) into the heifer calf equation determines the number of heifer calves sold by the representative U.S. producer in period $t$ :

$$
h_{t}=\beta\left(1-\gamma^{C}\right)\left(\chi_{t}+f_{t}\right)-f_{t+2} /\left(1-\gamma^{R}\right) .
$$

The total breeding stock in period $t$ is comprised of adult cows, first-calf heifers, and replacement heifers retained at $t-1$ which, using equation (16), is calculated as

$$
x_{t}=\chi_{t}+f_{t}+f_{t+1} /\left(1-\gamma^{R}\right) \text {. }
$$

Equations (16) and (18) define the total cattle stock in period $t$ to be

$$
y_{t}=\chi_{t}+f_{t}+\left(f_{t+1}+f_{t+2}\right) /\left(1-\gamma^{R}\right) .
$$

Finally, the number of bulls in the herd at time $t, b_{t}$, is identified with use of equation (18) as

$$
b_{t}=x_{t} / \phi
$$

where each bull services $\phi$ members of the breeding stock, which is taken as $\phi=29$

\footnotetext{
${ }^{13}$ Note that the gestation lag in the birth of steer calves in equation (15) is subsumed into a single period. That is, adult cows on January 1 have been bred previously and will calve in April or May. The sale of all culls and calves occurs subsequently in the same period at October 31 prices in the LMIC data.
} 
throughout to maintain consistency with LMIC budgets. Equations (15) and (17)-(20) describe the core of the simulation model.

Net profit for a manager of a given type is calculated from simulated revenues, costs, and capital gains in each period. In period $t$, define the value of the current cattle inventory as $I_{t}$, denote the spot market prices for heifer calves, steer calves, adult cows, and bulls, as $P_{t}^{H}, P_{t}^{S}, P_{t}^{C}$, and $P_{t}^{B}$, respectively, and let $\Delta b_{t}=b_{t}-b_{t-1}$ represent the change in bull inventory. Defining the arguments of the functions to be $\alpha_{t} \equiv\left(y_{t}, b_{t}\right), \bar{\alpha} \equiv(\bar{y}, \bar{b})$, and $\xi_{t} \equiv\left(P_{t}^{H}, P_{t}^{S}, P_{t}^{C}, P_{t}^{B}\right)$ to streamline notation, total revenue at $t$ is

$$
T R_{t}\left(\xi_{t}\right)=P_{t}^{H} h_{t}+P_{t}^{S} s_{t}+P_{t}^{C} c_{t}-P_{t}^{B}\left(\Delta b_{t+1}\right),
$$

and total cost in period $t$ is

$$
\text { (21) } \begin{aligned}
& T C_{t}\left(r_{t}, \xi_{t}, \alpha_{t}, \bar{\alpha}\right)= \\
&\left(1+0.5 r_{t}\right)\left[\psi_{t}\left(\alpha_{t}\right)+m_{t}\left(\alpha_{t}\right)+\omega T R_{i}\left(\xi_{t}\right)+l_{t}(\bar{\alpha})\right. \\
&\left.+u_{t}(\bar{\alpha})+a_{t}(\bar{\alpha})\right]+d_{t}(\bar{\alpha})+r_{t} I_{t}\left(\xi_{t}, \alpha_{t}\right),
\end{aligned}
$$

where $r_{t}$ is the real interest rate, $\psi_{t}$ is the cost of pasture, $m_{t}$ is winter feed cost, $\omega=0.03$ reflects the marketing cost on period $t$ sales, $l_{t}$ is labor cost, $u_{t}$ is utilities cost, $a_{t}$ is the cost of equipment repairs, $d_{t}$ reflects depreciation on buildings and equipment and the combined cost of taxes and insurance, and $I_{t}$ is the investment value of the cattle inventory. For analytic convenience, all costs except the last two terms, depreciation and the opportunity cost of inventory, are incurred at the midpoint of each period and are thus inflated by the factor $\left(1+0.5 r_{t}\right)$. Fixed costs in equation (21), which may vary over time but not over the stock level, are denoted with the arguments $\bar{\alpha}$, while variable costs are calculated for different inventory levels and age distributions using LMIC data on annual feed requirements of cows, first calf heifers, replacement heifers, and bulls. The variable cost components also include the opportunity cost of the cattle inventory, the last term in equation (21), which is incurred at rate $r_{t}$ on the investment value of the beginning inventory in period $t, I_{t}$. This investment value depends on the age distribution of the herd at $t$, which may differ across time as well as between the various management strategies.

To account for changes in the age distribution of the stock, the initial inventory is characterized by a uniform distribution of cows between the ages of 3 years and 9 years, after which the number of cows in the previous four cohorts declines linearly to zero at age
13. Changes in the age distribution over time are determined by the extent of culling in previous periods, where the culling decision is simplified here by assuming that all cows are culled from oldest to youngest in an ordered set that is numerically sorted by cohort. Thus, from the beginning inventory described above, all 13-year-old cows (the eldest cohort) are culled prior to the removal of any 12-year-old cows from the herd. For analytic convenience, attention is confined to the case where the market value of a cow declines linearly with age from a brood cow to a 13-yearold cull. Hence, denoting the value of a cow of age $i$ in period $t$ as $V_{t, i}$, the investment value of the cattle inventory is

$$
\begin{gathered}
I_{t}\left(V_{t, 1}, V_{t, 5}, \xi_{t}, \alpha_{t}\right)= \\
x_{t, 1} V_{t, 1}+\sum_{i=2}^{12} x_{t, i} V_{t, 5}[1-(i-5)] \\
\left(\frac{V_{t, 5}-P_{t}^{C}}{7}\right)+P_{t}^{B} b_{t}
\end{gathered}
$$

where $x_{t, i}$ denotes the number of cows of age $i$ in period $t$. Thus, $x_{t, 1} \equiv \rho_{t}$ denotes replacement heifers and $x_{t, 2} \equiv f_{t}$ first-calf heifers at $t$. The value of a replacement heifer $\left(V_{t, 1}\right)$, breeding cow $\left(V_{t, 5}\right)$, cull cow $\left(P_{t}^{C}\right)$, and bull $\left(P_{t}^{B}\right)$ are taken from LMIC data.

Substitution of equation (22) into the cost equation (21) allows net business returns to be calculated for a cattle operation in period $t$ as

$\pi_{t}\left(r_{b} \xi_{t}, \alpha_{t}, \bar{\alpha}\right)=T R_{t}(\xi)-T C_{t}\left(r_{t}, \xi_{t}, \alpha_{t}, \bar{\alpha}\right)+\Delta I_{t}$,

where $\Delta I_{t}=I_{t}-I_{t-1}$ denotes the change in inventory value at the beginning of period $t$. For comparative purposes, net return on assets is also considered, which is calculated as

$$
\begin{aligned}
& \sigma= \\
& \pi_{t}+r_{t} I_{t}+0.5 r_{t}\left(\psi_{t}+m_{t}+\omega T R_{t}+l_{t}+u_{t}+a_{t}\right) \\
& I_{t}
\end{aligned} .
$$

All monetary values are expressed in real 1998 dollars.

\section{Empirical Results}

Figure 1 shows the relationship between the detrended U.S. cattle inventory numbers and the annual slaughter numbers over the period, where both series have been normalized for convenience to a representative producer with an average of 100 head and an average 


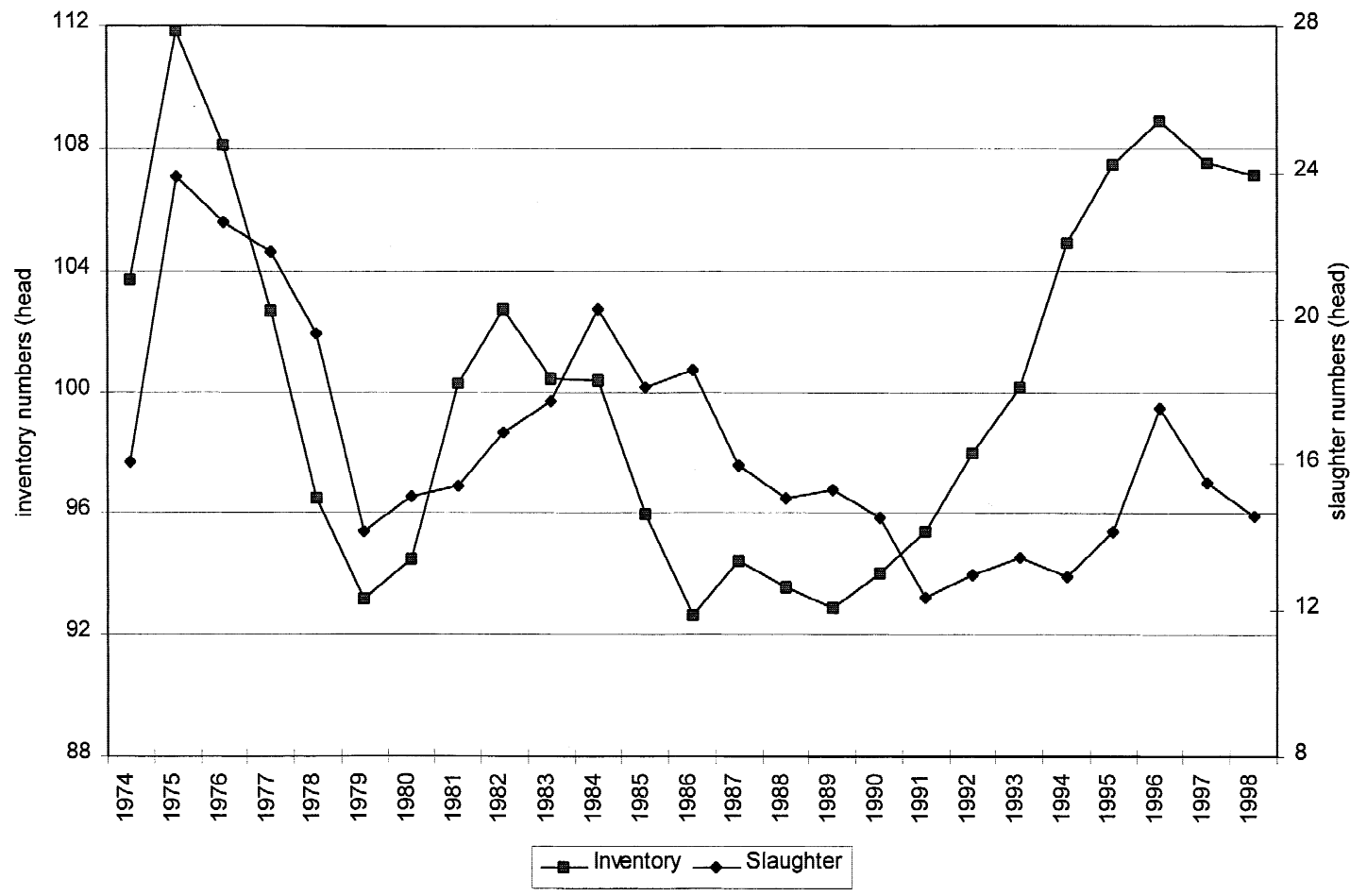

Figure 1. Beef cow inventory and slaughter numbers for the representative U.S. producer, 1974-98

culling rate of $16.67 \% .{ }^{14}$ The variation between the U.S. inventory level and the slaughter numbers, which is particularly apparent in the latter periods, suggests the use of a model with variable culling levels over time. Thus, changes in the inventory level of a representative producer in the simulation depend both on the addition of first-calf heifers into the stock through replacement and on the culling of adult cows at each point in time.

Throughout, all net returns (economic profits) reported are for a business with an average herd size of one cow over the 197498 period. Figure 2 shows the relationship between annual deviations from the 1974-98 average real net return and inventory numbers for the representative U.S. producer. ${ }^{15}$ Notice that an inverse relationship exists between the level of inventory and the deviation in net return. With few exceptions, each period with

\footnotetext{
${ }^{14}$ Our 100-head herd conforms to the U.S. Department of Agriculture (USDA) definition of a beef cow: cows that have calved at least once by January 1 . The LMIC reports a $14 \%$ culling rate against the entire cow inventory, which includes first-calf heifers that have not yet calved on January 1 . To accommodate this definitional discrepancy, we adjust the average culling rate to $0.14 /(1-0.16)=0.1667$.

${ }^{15}$ In each year, the nominal net return is adjusted to 1998 dollars using the PCE price deflator.
}

an inventory level above the mean beef cow inventory corresponds with below-average profitability for the representative U.S. producer. This result provides some casual evidence that exogenous shocks are not unique determinants of the cattle cycle, as there appears to be a systematic relationship between inventory numbers and profitability: the representative producer consistently holds low cattle inventory in periods of above-average profitability. In periods of relatively high net return, the representative producer is unable to fully capitalize on the profit margin with correspondingly large cattle sales. Conversely, when profitability is relatively low, the representative producer consistently holds a larger-than-average inventory.

For comparative purposes, figures 3 and 4 show the deviation in net return from the average 1974-98 level and inventory numbers for the constant-inventory and countercyclical producer. Unlike the representative producer, the countercyclical producer consistently manages to hold low levels of inventory in periods of low net returns and high inventory in periods of high net returns.

Table 2 presents the calculations of real net returns and the rate of return on breeding 


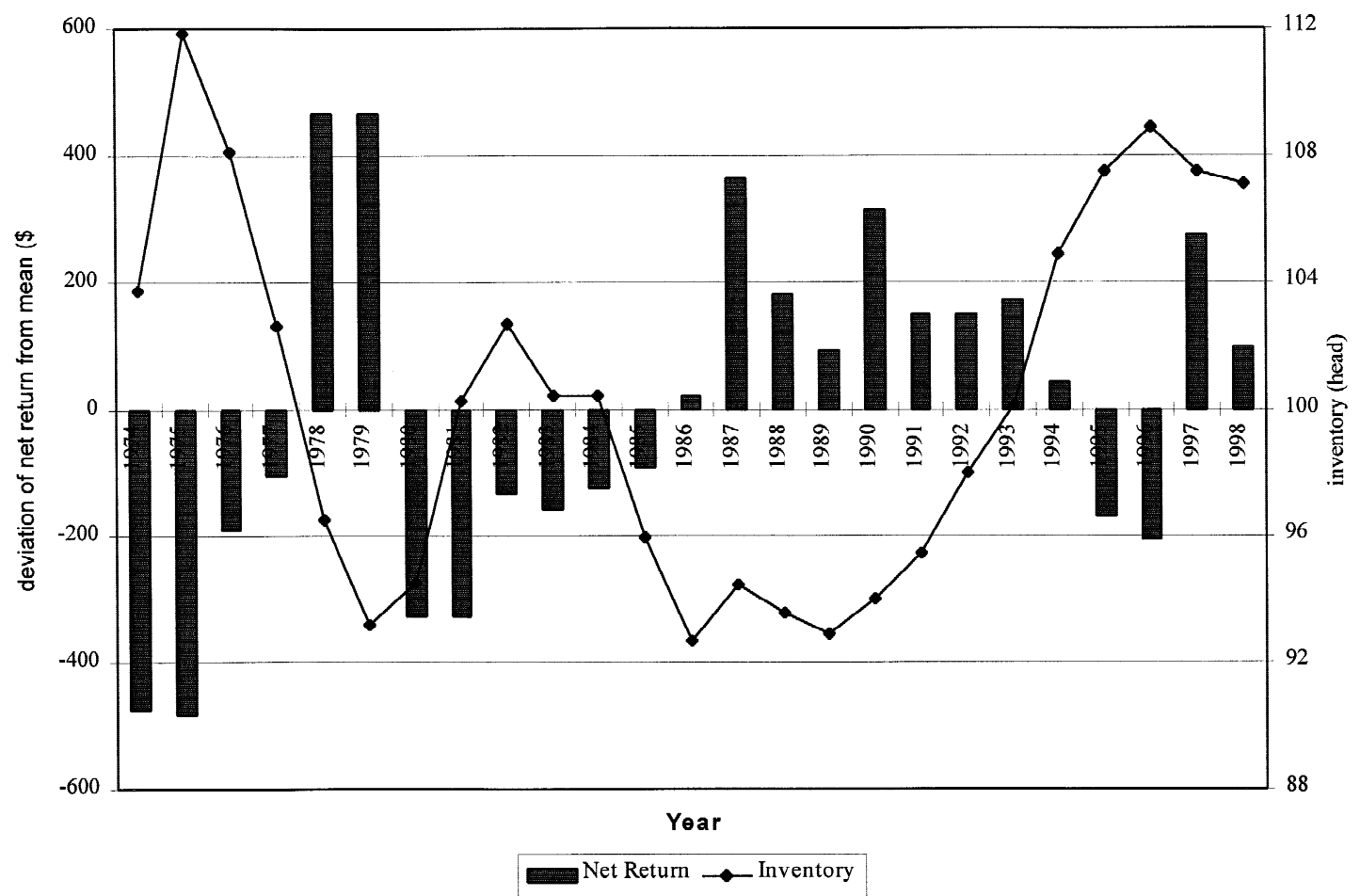

Figure 2. Deviation of net return and inventory for the representative U.S. producer, 1974-98

stock assets for the various management approaches. The calculated rate of return on assets for each type of producer, on average, is below the market rate of interest, which leads to a negative average net return. Over the 1974-98 period, a representative producer with an average herd size of one cow received a mean net return of $-\$ 137.94$. In contrast, a producer who maintained a constant inventory of exactly one cow in every period averaged $-\$ 125.39$, while a countercyclical manager received a mean net return of $-\$ 113.46$. The average net return in cow-calf production is negative for all types of producers considered, as the data capture three peaks and two troughs in the cattle inventory cycle, which roughly corresponds to two peaks and three troughs in the price cycle. ${ }^{15}$

We test the hypotheses derived in the theoretical model using a small sample Wilcoxon signed-rank test on the difference in mean net return for the representative U.S. producer and constant inventory manager (Wilcox, pp. 322-24). ${ }^{16}$ Hypothesis 1 implies that the

\footnotetext{
${ }^{16}$ Presumably, if our data set captured several more complete cycles, the average economic return would approach zero for the representative U.S. producer.
}

representative U.S. producer should have a higher average net return than the constant inventory manager if the cattle cycle is driven exclusively by exogenous shocks. This possibility is rejected at the $1 \%$ level with the small sample Wilcoxon test. ${ }^{17}$ If the cattle cycle is driven entirely by exogenous shocks, hypothesis 1 also implies that the representative U.S. producer should have a higher rate of return on assets than the constant inventory manager. This possibility is rejected at the $10 \%$ level with the small sample Wilcoxon test (at $7.5 \%$ with a paired t-test). Overall, this evidence indicates that the U.S. cattle cycle is not exclusively driven by exogenous demand and cost shocks, which suggests that the market timing effect plays a significant role in determining the various phases of the cattle cycle. $^{18}$

A related result is reported by Bentley and Shumway, who compare discounted net returns from various adaptive (i.e., closed-loop)

\footnotetext{
${ }^{17}$ The small-sample Wilcoxon signed-rank test, unlike a paired t-test, does not presume a normal distribution nor does it depend on independence of the two series.

18 This hypothesis is also rejected at the $1 \%$ level using a standard paired t-test.
} 


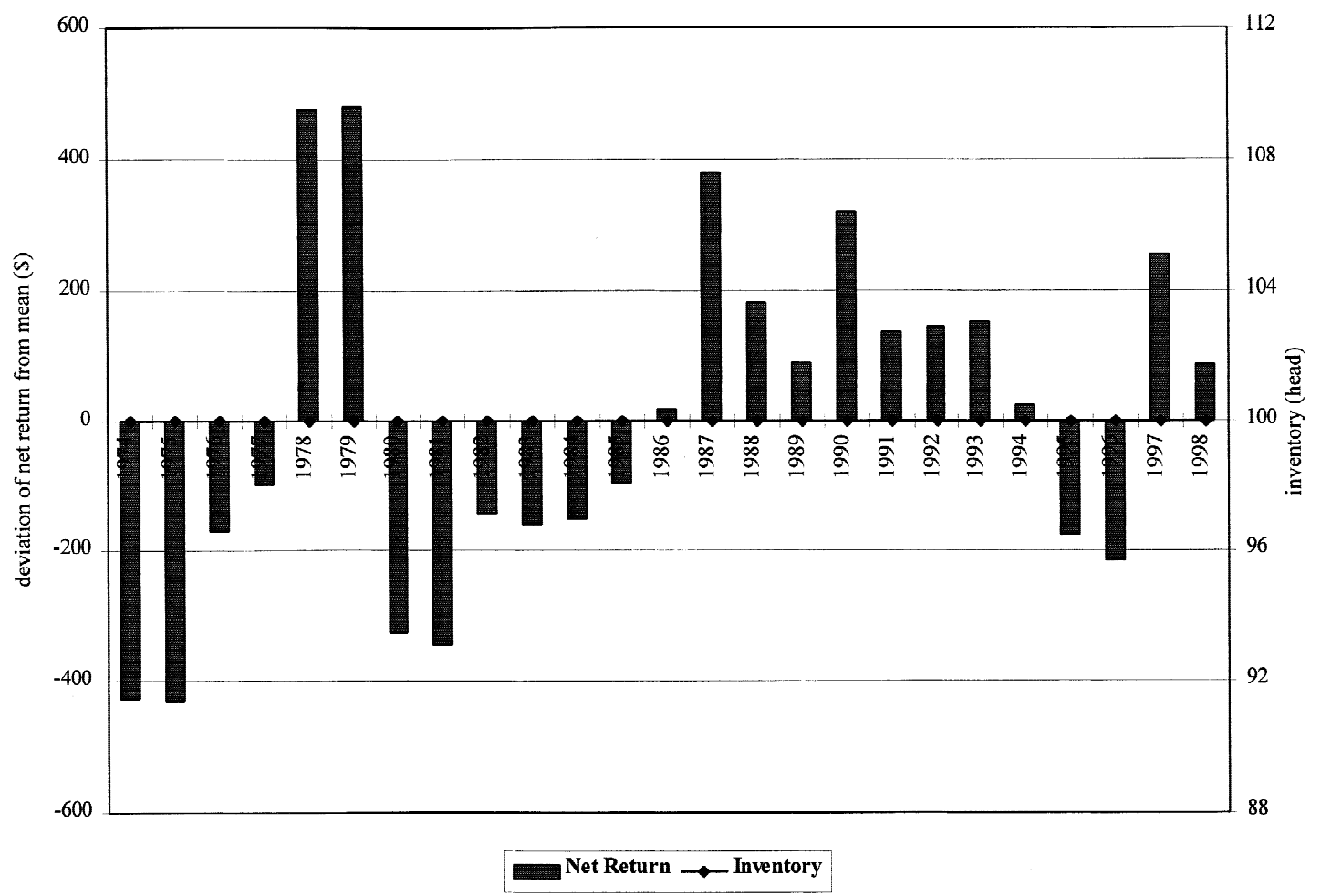

Figure 3. Deviation of net return and inventory for the constant inventory producer, 1974-98

inventory management strategies over the 1958-67 period. In their simulation model, maintaining a constant inventory provided a higher present value of discounted net revenue relative to an adaptive plan in which the breeding stock was modified "optimally" each year by reestimating a cyclical forecasting equation. That is, a producer who projected the future price cycle and responded accordingly prior to choosing output in each period performed worse than a manager who did not vary output at all. In light of the previous discussion, the implication is that when producers project cyclical prices, they respond through a planned market timing effect by altering output levels in a corresponding fashion. Given similar information to form their price expectations, high prices in future periods are never realized if public forecast information induces systematic rebuilding in the economy.

While the evidence suggests that market timing effects influence the cattle cycle, the results in table 2 indicate that exogenous shock effects are also important. There are several periods in which exogenous shock effects appear to dominate the market timing effect, as profitability is higher for the repre- sentative producer in 1981, 1984, 1991, 1993 94, and 1997-98 than for other managers. Indeed, the overall performance ranking of the three types of manager reverses in these periods, as the countercyclical manager has the lowest net profit. Exogenous shock effects may be particularly important in these years: for example, in 1981, 1984, and 1994, U.S. corn prices were especially high.

Table 2 also shows that each period of positive and negative net return exactly coincides for all three types of producer. Evidently, even a countercyclical producer earns a negative net return in a period of negative industry profitability. This similarity in net returns across the various producers indicates that periods of above- or below-average profitability are largely determined by prevailing market prices, whereas the magnitude of the deviation in a given period is influenced by the volume of sales. This finding provides further evidence that the market timing effect is an important factor that drives the cattle cycle, as periods of negative net return are systematically related to high levels of inventory in the economy and not a result induced solely by random events.

From a farm management perspective, it is 


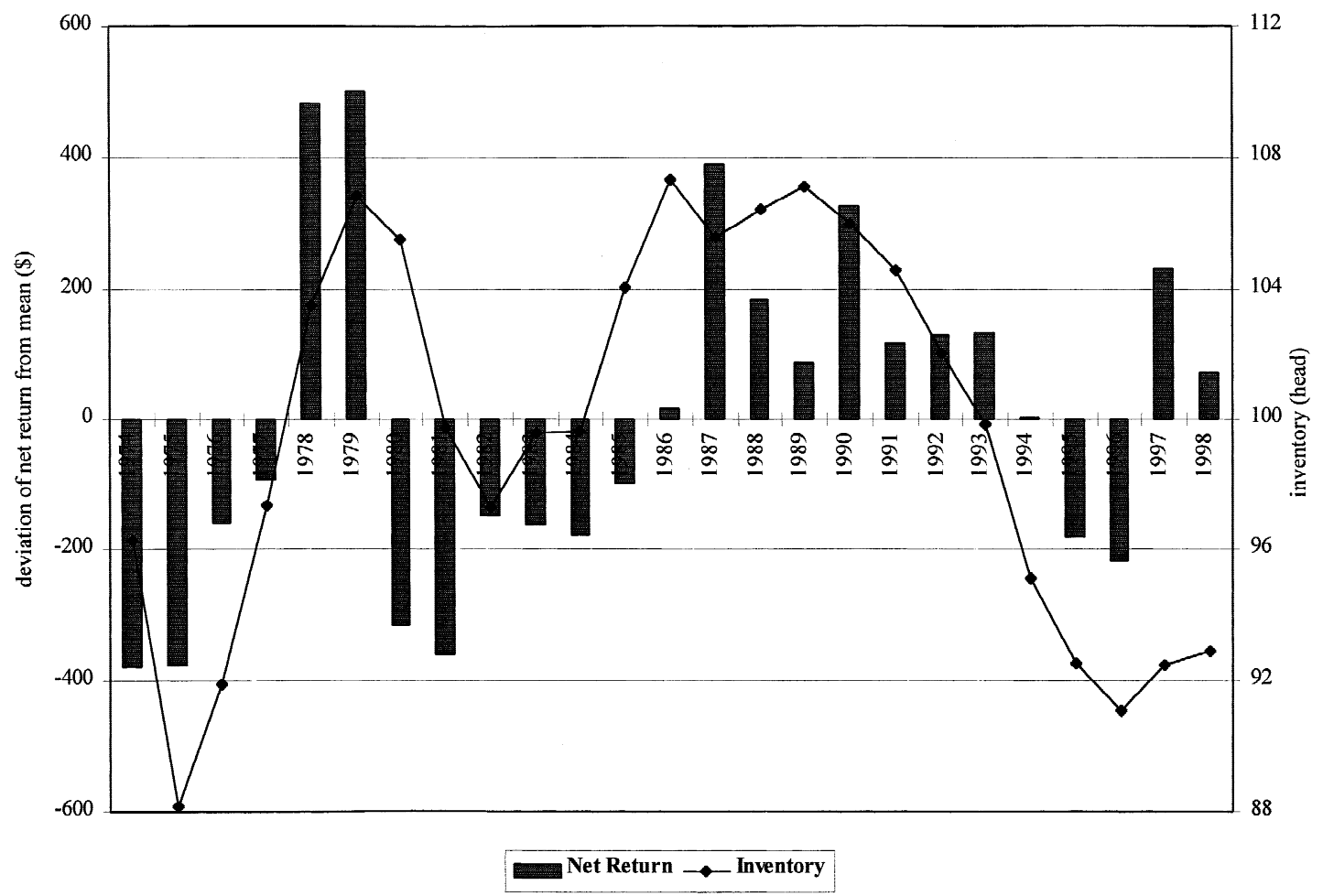

Figure 4. Deviation of return and inventory for the countercyclical producer, 1974-98

noteworthy that the countercyclical manager performs only $\$ 24.48$ better, on average, than the representative U.S. producer. Roughly half of this gain, or $\$ 12.55$ on an average herd size of one head, can be acquired through constant inventory management, which involves no special market insights. ${ }^{19,20}$

\section{Concluding Remarks}

This article provided an examination of two potential factors that influence the cattle cycle: an exogenous shock effect and a market timing effect. The theoretical model isolated each factor and developed an important insight regarding the relative economic perfor-

\footnotetext{
${ }^{19}$ Following the suggestion of a reviewer, we also conducted a simulation that used culling rates directly consistent with USDA slaughter numbers, which implies an average culling rate of $11.2 \%$, rather than the normalized LMIC values. Results were fundamentally unchanged, with the constant inventory net return (rate of return on assets) statistically greater than that of the representative producer at the $1 \%(10 \%)$ level.

${ }^{20}$ There is also a difference in the level of risk borne by the representative producer and constant inventory manager. Results available from the authors show that the difference in mean net return between the two approaches is statistically insignificant in periods of positive net return, while the constant inventory manager performs significantly better in periods of negative net return (at the $1 \%$ level).
}

mance of a representative U.S. producer and a producer who deviated from the aggregate to maintain a constant inventory over the 1974-98 period. The analysis demonstrated that a representative producer should outperform a constant-inventory manager for a cattle cycle driven exclusively by exogenous shocks. Conversely, a representative producer should underperform a constantinventory manager under cyclical cattle prices derived by market timing effects. This conceptual observation led to an empirical examination of net returns from alternative inventory management regimes.A simulation of net returns to cow-calf production demonstrated that the profitability of a representative producer varied inversely with U.S. beef cow inventory levels throughout the cattle cycle. A clear ranking was developed with regards to the performance of the various management approaches: the mean net return for given herd size over the $1974-98$ period was significantly greater for the constant inventory manager than for the representative producer. This result indicated that the market timing effect has an important influence on the determination of the various phases of expansion and contraction in the cattle cycle. 
Table 2. A Comparison of Net Returns Per Head and Rates of Return on Assets for the Representative U.S. Cattle Producer, Constant-Inventory Producer, and Countercyclical Producer (in 1998 Dollars)

\begin{tabular}{|c|c|c|c|c|c|c|}
\hline \multirow[b]{2}{*}{ Year } & \multicolumn{2}{|c|}{$\begin{array}{l}\text { Representative } \\
\text { U.S. Producer }\end{array}$} & \multicolumn{2}{|c|}{$\begin{array}{c}\text { Constant-Inventory } \\
\text { Producer }\end{array}$} & \multicolumn{2}{|c|}{$\begin{array}{l}\text { Countercyclical } \\
\text { Producer }\end{array}$} \\
\hline & $\begin{array}{l}\text { Net Return } \\
\text { (\$/head) }\end{array}$ & $\begin{array}{c}\text { Rate of } \\
\text { Return (\%) }\end{array}$ & $\begin{array}{l}\text { Net Return } \\
\text { (\$/head) }\end{array}$ & $\begin{array}{c}\text { Rate of } \\
\text { Return }(\%)\end{array}$ & $\begin{array}{l}\text { Net Return } \\
(\$ / \text { head })\end{array}$ & $\begin{array}{c}\text { Rate of } \\
\text { Return }(\%)\end{array}$ \\
\hline 1974 & $-\$ 611.95$ & -19.2 & $-\$ 550.94$ & -19.4 & $-\$ 494.31$ & -19.7 \\
\hline 1975 & $-\$ 621.64$ & -24.6 & $-\$ 554.66$ & -24.7 & $-\$ 489.61$ & -24.5 \\
\hline 1976 & $-\$ 329.17$ & -11.6 & $-\$ 294.86$ & -10.7 & $-\$ 272.41$ & -10.3 \\
\hline 1977 & $-\$ 245.49$ & -7.2 & $-\$ 223.77$ & -5.8 & $-\$ 207.08$ & -4.7 \\
\hline 1978 & $\$ 328.66$ & 35.4 & $\$ 350.12$ & 36.5 & $\$ 369.39$ & 37.5 \\
\hline 1979 & $\$ 329.44$ & 33.4 & $\$ 354.73$ & 33.7 & $\$ 389.47$ & 34.7 \\
\hline 1980 & $-\$ 467.58$ & -8.5 & $-\$ 450.94$ & -7.6 & $-\$ 430.50$ & -6.5 \\
\hline 1981 & $-\$ 466.26$ & -9.6 & $-\$ 470.17$ & -9.9 & $-\$ 475.21$ & -10.3 \\
\hline 1982 & $-\$ 273.21$ & -0.3 & $-\$ 267.90$ & -0.1 & $-\$ 262.89$ & -0.0 \\
\hline 1983 & $-\$ 296.13$ & -5.7 & $-\$ 285.11$ & -5.0 & $-\$ 274.95$ & -4.3 \\
\hline 1984 & $-\$ 264.63$ & -4.4 & $-\$ 276.60$ & -4.9 & $-\$ 291.39$ & -5.7 \\
\hline 1985 & $-\$ 231.64$ & -4.3 & $-\$ 222.87$ & -3.1 & $-\$ 212.81$ & -1.9 \\
\hline 1986 & $-\$ 118.42$ & 2.2 & $-\$ 108.10$ & 3.6 & $-\$ 97.45$ & 4.9 \\
\hline 1987 & $\$ 227.74$ & 35.2 & $\$ 252.58$ & 35.8 & $\$ 277.99$ & 36.5 \\
\hline 1988 & $\$ 43.79$ & 16.9 & $\$ 55.78$ & 17.5 & $\$ 68.82$ & 18.1 \\
\hline 1989 & $-\$ 44.78$ & 9.6 & $-\$ 36.30$ & 10.5 & $-\$ 26.61$ & 11.4 \\
\hline 1990 & $\$ 177.92$ & 29.4 & $\$ 195.20$ & 29.6 & $\$ 213.49$ & 29.8 \\
\hline 1991 & $\$ 14.45$ & 13.3 & $\$ 9.55$ & 12.8 & $\$ 3.91$ & 12.2 \\
\hline 1992 & $\$ 14.36$ & 12.3 & $\$ 18.03$ & 12.5 & $\$ 16.83$ & 12.2 \\
\hline 1993 & $\$ 33.91$ & 12.8 & $\$ 27.40$ & 12.2 & $\$ 18.29$ & 11.4 \\
\hline 1994 & $-\$ 94.31$ & 3.0 & $-\$ 102.46$ & 2.2 & $-\$ 111.88$ & 1.3 \\
\hline 1995 & $-\$ 307.90$ & -13.8 & $-\$ 300.38$ & -14.0 & $-\$ 292.89$ & -14.4 \\
\hline 1996 & $-\$ 343.91$ & -21.2 & $-\$ 341.16$ & -22.1 & $-\$ 331.55$ & -22.7 \\
\hline 1997 & $\$ 137.55$ & 27.0 & $\$ 128.42$ & 26.3 & $\$ 118.66$ & 25.7 \\
\hline 1998 & $-\$ 39.24$ & 6.6 & $-\$ 40.25$ & 6.4 & $-\$ 41.75$ & 6.1 \\
\hline Average: & $-\$ 137.94^{\mathrm{a}}$ & 4.2 & $-\$ 125.39^{\mathrm{a}}$ & 4.5 & $-\$ 113.46$ & 4.7 \\
\hline
\end{tabular}

${ }^{\mathrm{a}}$ Wilcoxon statistic: $W=272$.

An obvious shortcoming of a simulation model of inventory management is the degree of simplification necessary to refine the various complexities of cattle production. Through the construction of a representative producer from U.S. inventory data, the analysis suppressed several aspects of individual farm management that are potentially important, such as the ability to control production costs or to modify the operating scale over time. As with farm size in general, cow-calf operations tended to expand in size during the 1974-98 period of study, and, commensurately, the average cost per head would have decreased if significant scale economies exist. Nonetheless, the analysis has provided evidence that market timing is a significant determinant of the cattle cycle.

Further research is needed to determine the features that comprise the market timing effect. The analysis provided evidence for the existence of the market timing effect; how- ever, its underlying cause remains to be determined. Whether the market timing effect is determined largely by planned factors, such as the incentive for producers to attempt countercyclical management, or by unplanned factors, such as credit constraints that force producers to sell at certain, and perhaps inopportune, times is an issue that remains at this point unresolved. Hopefully, our identification of endogenous factors that influence the cattle cycle, which suggests a number of possibly important and certainly interesting economic consequences, will provide direction for future research.

\section{References}

Bentley, E., and C.R. Shumway. "Adaptive Planning Over the Cattle Cycle." S. J. Agr. Econ. 13(July 1981):139-48. 
Bierlen, R., P.J. Barry, B.L. Dixon, and B.L. Ahrendsen. "Credit Constraints, Farm Characteristics, and the Farm Economy: Differential Impacts on Feeder Cattle and Beef Cow Inventories." Amer. J. Agr. Econ. 80(November 1998):708-23.

Foster, K.A., and O.R. Burt. "A Dynamic Model of Investment in the U.S. Beef-Cattle Industry." J. Bus. and Econ. Statist. 10(October 1992):419-26.

Hayes, D.J., and A. Schmitz. "Hog Cycles and Countercyclical Production Response." Amer. J. Agr. Econ. 69(November 1987):762-70.

Jarvis, L.S. "Cattle as Capital Goods and Ranchers as Portfolio Managers: An Application to the Argentine Cattle Sector." J. Polit. Econ. 82(May/June 1974):489-520.

Lucas, R. "Some International Evidence on Output-Inflation Tradeoffs." Amer. Econ. Rev. 63(June 1973):326-34.
Livestock Marketing Information Center. Englewood CO.

Rosen, S. "Dynamic Animal Economics." Amer. J. Agr. Econ. 69(August 1987):547-57.

Rosen, S., K.M. Murphy, and J.A. Scheinkman. "Cattle Cycles." J. Polit. Econ. 102(June 1994):468-93.

Rucker, R.R., O.R. Burt, and J.T. LaFrance. "An Econometric Model of Cattle Inventories." Amer. J. Agr. Econ. 66(May 1984):131-44.

Schmitz, J.D. "Dynamics of Beef Cow Herd Size: An Inventory Approach." Amer. J. Agr. Econ. 79(May 1997):532-42.

Trapp, J.N. "Investment and Disinvestment Principles with Nonconstant Prices and Varying Farm Size Applied to Beef-Breeding Herds." Amer. J. Agr. Econ. 68(August 1986):691-703.

Wilcox, R.R. New Statistical Procedures for the Social Sciences: Modern Solutions to Basic Problems. New Jersey: Lawrence Erlbaum Associates, Inc., 1987. 